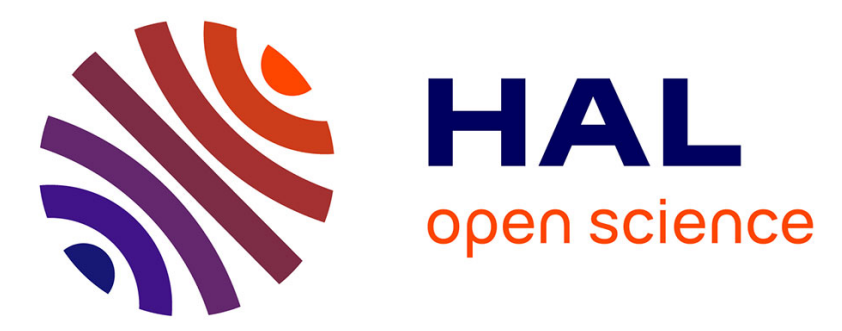

\title{
From 18th Century Chemistry to 21st Century Creative Class: A Sociological Perspective on Policies Intended to Promote Local Economic Development Based on Innovation
}

Michel Grossetti

\section{To cite this version:}

Michel Grossetti. From 18th Century Chemistry to 21st Century Creative Class: A Sociological Perspective on Policies Intended to Promote Local Economic Development Based on Innovation. Rolf Sternberg; Gerhard Krauss. Handbook of research on entrepreneurship and creativity, Edward Elgar, pp.275-295, 2014, 978-1-78100-442-5. halshs-01387647

\section{HAL Id: halshs-01387647 \\ https://shs.hal.science/halshs-01387647}

Submitted on 25 Oct 2016

HAL is a multi-disciplinary open access archive for the deposit and dissemination of scientific research documents, whether they are published or not. The documents may come from teaching and research institutions in France or abroad, or from public or private research centers.
L'archive ouverte pluridisciplinaire HAL, est destinée au dépôt et à la diffusion de documents scientifiques de niveau recherche, publiés ou non, émanant des établissements d'enseignement et de recherche français ou étrangers, des laboratoires publics ou privés. 


\title{
From XVIII ${ }^{\text {th }}$ century chemistry to the XXI $^{\text {th }}$ creative class: a sociological perspective on policies intended to promote local economic development based on innovation
}

Michel Grossetti, 2014, "From 18th century chemistry to the 21 st century creative class: a sociological perspective on policies intended to promote local economic development based on innovation", in Rolf Sternberg and Gerhard Krauss (dir.), Handbook of research on entrepreneurship and creativity, Edward Elgar, Cheltenham, UK • Northampton, MA, US.A, pp. 275-295.

\begin{abstract}
In 1781, the "States of Languedoc", a French province, recruited at the University of Montpellier chemist Jean-Antoine Chaptal to develop the chemical industry in this region. The idea of using scientific and technological innovation to promote local economic development is not new. This idea has generated numerous policies since Chaptal. Some rely on the development of universities capable of training a skilled workforce and to provide scientific support to industry. Others give more purpose to promote the creation of new firms or the networking of existing ones. They do so in ways very different, from technology parks to policy of "clusters" funding projects that involve local collaborations. Finally, more recently, policies based on the theory of "creative class" have sought to attract not companies but persons whose profession is related to innovation activities, that they are technical, economic or cultural. This text present a review of these policies, from a series of studies conducted in France and Europe. The text will not seek to make a survey of public policies analysis, but rather to give a view based on some field studies. The effect of public policies can be of three types: non-existent, simple maintenance of existing balances, changes in these balances. With regard to the policies of local development based on innovation, if the first two kinds are widespread, the third is much rarer. This is partly because many policies are based on misconceptions about the mobility of firms and individuals (business parks, creative class), or the effect of simple spatial proximity of linking people or companies (effect "cafeteria" or "coffee machine"). The search for quick fixes, inexpensive and visible, favors policies which are usually ineffective.
\end{abstract}


Policies to promote local economic development are numerous, they are produced by various actors involving the same two issues: to ensure sustainable development, and to maintain or to increase jobs. Many rely on technological activities that are expected to be less sensitive to the effects of competition on the cost of labor and are thusly more promising. The range of policy instruments to encourage the growth of these activities is wide: building equipment for higher education and research, encouraging researchers of universities to collaborate with local companies, technology parks, incubators, "nurseries" for startups, programs supporting the creation of innovative companies, creation of venture capital funds, technological animation, aid to technology transfer, etc. For fifteen years, policies designed to attract persons believed to form a "creative class" have also been added: scientists, artists, entrepreneurs, renowned artisans, etc.

Some of these policies are very old. For instance, a few years before the French Revolution the states of Languedoc province, created a university chair in chemistry to contribute to the development of a local chemical industry. This is one of the oldest known examples of science policy oriented towards local economic development. In fact, the chemist recruited, Jean-Antoine Chaptal, founded factories of soda, sulfuric acid, sulfate of iron and copper, employing more than 1500 workers circa 1785. Later, there were other examples of political rapprochement between higher education and industry, such as the creation of the Technischen Hochschulen in Germany, the Ecole Centrale des Arts and Manufactures in France, or, still in France, the creation of academic departments or facultés of science technical institutes between 1880 and 1914. Preceding the connection between academic science and industry, there were, of course, all the policies designed to implement universities or other higher education institutions in cities previously lacking them. The growing number of students and research activities allowed in many countries an increasing density of the university towns' network. During periods of growth, a kind of competition develops between cities wishing to acquire higher education institutions, although the conditions of this competition vary greatly between countries and periods. However, expansion is a common feature of systems of higher education and research, we know very little of institutional closures.

The direct link between research and industry has been systematically set out in the twentieth century policies, and has mostly been inspired by the arrangements put in place at the Massachusetts Institute of Technology (Etzkowitz, 2003). Indeed, it is here that the main concepts emerged: venture capital, technology transfer, technical consultancy, and even industrial zone hosting companies created from research. These ideas were implemented in the 1930s in California by Franck Terman, a graduate of MIT, director of the Department of Electrical Engineering of the Stanford University and founder of the Stanford Research Park, the starting point of the famous Silicon Valley. Discussions continue between specialists to decide the relative importance of this science park to the success of Silicon Valley, or the later arrival of the company founded by William Shockley (Nobel Prize in Physics for the development of the transistor) or the existence in the region of technical know-how. The issue in this debate is the priority given to causes which are "political" (the creation of the business park) "economic" (the location decision of Shockley) or "structural" (the existence of a skilled workforce). In any case, it is certain that the success of Silicon Valley has led to the creation of numerous technology parks in the world and to the proliferation of policies based on those that were put in place there. Initially, the building of technology parks was based on the idea that it was necessary to have facilities to accommodate companies from local academic research. Later emerged the idea that they could be factors for attracting foreign enterprises, and that the concentration of firms in a relatively small space should promote the 
establishment of local partnerships. Some have thought that it was necessary to accompany this concentration by shared public spaces in order to encourage meetings. In many parks restaurants or cafeterias were built and expected to generate collaboration by what some park managers called the "cafeteria effect". A variant of this idea is to focus on the installation of a coffee machine in a building shared by several companies. More proactive policies offered direct services to start-ups: low cost facilities, commercial or legal advices, a joint secretariat. These shared and equipped spaces were called "nurseries" or "incubators". Park managers have also recruited people responsible for putting companies in contact with each other or with academic research laboratories. In addition to daily counseling, these people usually organize various activities: breakfasts, conferences, working groups on common themes (quality, free software, etc.).

Finally, during the last fifteen years, "lighter" policies have been tried. Among these are incentives to network using competitive projects like German "clusters" of biotech or French "competitivity poles". In this case, the local or national governments encourage companies and laboratories to compete in joint projects where the winners are awarded a label and public funding. Additionally, there were also some attempts to create favorable conditions for attracting people in so called "creative" occupations. In this second case, the local authorities conduct planning policies designed to develop neighborhoods that are supposed to be fitted to targeted social groups, developing cultural opportunities based on their tastes, and often providing direct financial incentives to encourage them to settle in their city.

Today, all these policies coexist, and new ones are added to the pre-existing, rather than replacing them. They have been the subject of numerous studies from various theoretical frameworks, including economic geography, regional studies, management science, political science, sociology of organizations, innovation studies or science studies.

My goal in this paper is not to make a survey of this enormous amount of work and adding another study to it. I wrote instead an essay on innovation policies based on my own research which for twenty five years has mostly focused on the case of France (especially provincial towns and more specifically the one where I live, Toulouse) as well as some research on several European countries I participated in. Therefore, this paper presents a personal perspective, based on my own empirical research, and some other studies, and not a classical academic paper with a complete survey of literature, and the exposal of one particular study. I apologize for this unusual format, and for using so much my own work, but I think it is the most suitable for a synthetic collection of texts like this handbook.

I present in the first part the studies that I use as a basis for the essay. Some of them have been published in English, but some other have only been published in French. I summarize here the main studies and their results. In the second part of the text, I will present an analysis of the necessary conditions for the development of innovation activities based on local relationships between companies and academic research. This analysis will serve as the background for the ensuing evaluation of different types of policies listed. I will first examine policies oriented at higher education and research. Then I will focus on policies for enterprises, whether for attracting foreign companies or encouraging the creation of local businesses. Then I will turn to policies seeking to foster relationships between companies or laboratories of the same site. Finally, I will discuss the policies designed to attract "creative" workers. 


\section{Empirical basis of an essay on innovation policies.}

I would again like to apologize for the presentation of my previous work, but these studies are the main basis of the analysis to be presented in the following sections. These studies have been conducted from the perspective of economic sociology. It is close to the work of Harrison White, Mark Granovetter, AnnaLee Saxenian, Walter Powell, and other scholars who studied the embeddedness of economic activities in social structures (Di Maggio and Zukin, 1990). Some of these studies focus on a set of French cities, others on the whole of France, or a series of European cities. Their intersection is the city of Toulouse. I begin with a brief presentation of the industrial history of the city and an analysis of one of its industrial clusters. Then I shall focus on studies on the embeddedness of economic activities in social networks (relations between academic laboratories and firms, creation of innovative companies). Finally, I will present a study of the creative class in Europe.

\section{French scientific system, clusters in Toulouse}

Toulouse is an interesting case in the French innovation system. This city shares with Grenoble and Nancy the characteristic of having since a long time academic institutions specialized in engineering (Peyroux, Grossetti and Eckert, 2009). At the beginning of the $20^{\text {th }}$ century, Toulouse was a sleepy regional metropolis (150,000 inhabitants) that had largely missed the Industrial Revolution. But the city developed soon a niche in higher education, research and high technologies due to a wide range of national policies as well as local impulses. Between 1906 and 1909, the Toulouse faculty of science, then headed by the future Nobel Prize Paul Sabatier, created three technical institutes: chemistry, electrical engineering, agronomy (Grossetti, 1995). The electrical engineering institute, the most successful, benefited from an important financing by the Toulouse municipality. In the 1930's emerged a new specialization in chemical engineering and in fluid mechanics.

After World War 2 emerged a new set of research institutions in automatics, system analysis and digital calculation, mostly because of the presence of the above mentioned technical institutes. Though, Toulouse was in the 1950's still in search of economic development. The aeronautics industry that had emerged during the First World War (1917) under the leadership of a wagon manufacturer, Latécoère, enjoyed after WWII full support from the State as well as the interest of local officials. The combination of local lobbying and national policies was a key impulse to the fast development of this industry and related activities. The primary growth impulse was the transfer of several national Higher Engineering Schools in the fields of aeronautics in the 1960's. The creation of an establishment of the National Centre for Spatial Studies, (CNES, 1961) draw locally a number of sub-contractors in computer sciences, and later on firms from space sector (Matra, Alcatel). Entrepreneurial logics also played a key role in economic development and specialization. The European aerospace complex developed around Airbus after 1974 became one of the main regional economic driving forces. Satellites manufacturing was the first industry in Toulouse to connect with the local research \& higher education system during the 70's, and the shifting of the aircraft industry from electromechanical technology to digital technology (Airbus A320 program) in the 80's represented another major bifurcation. Another key impulse came from the establishment of a then state-owned computer company (CII) and of Motorola (a major manufacturer in electronics). The decentralization of the French meteorological institute in 1982 led to a growing demand for calculation infrastructures and services. The needs of local high-tech industry boosted the development of technological service firms (software engineering, 
information storage, artificial intelligence, communication). Within a few years a 'local competency system' was born (Grossetti and Zuliani, 2011). This evolution was accompanied by the recruiting of a highly qualified workforce that had been predominantly educated within the local academic system.

Toulouse also benefited of French policy of creating "competitiveness poles". Jean-Marc Zuliani and I made a hundred of interviews between 2001 and 2006 with persons working in executive position in the firms or laboratories. Our analysis concludes that Toulouse " onboard systems » cluster is by no way the result of the current policy "competitiveness poles". It's the contrary: the "competitiveness pole" is the result of a pre-existing socio-economic cluster. The policy reinforce the socio-economic cluster but without modifying its structure. In Toulouse's on-board systems cluster, private economic actors mainly use cluster policies as an opportunity to do the same thing that before with some additional money. Some actors (aerospace industry subcontractors) weakly connected with the cluster use the pole to better connect themselves to the whole local dynamics and networks already well structured. Some other actors (principals), which were weakly interconnected before, created more direct links and learn to work together for developing some specific technologies. Some firms (big subcontractors) are more involved in R\&D activities. The sharing of knowledge is probably increasing and it's certainly more formally organized. The convergence of technologies in different sectors is probably increasing. The main results of the new cluster policies had the effect of strengthening an already existing socio-economic cluster. That case is an example of the strengths and limits of cluster policies as revealed by an analysis of the practices of private economic and scientific actors: when they work, it's often because they water already wet places.

As in most cases, Toulouse's industrial clusters are underpinned by social networks. The effect of these networks can be studied from collaborations between laboratories and companies or from the creation of new firms.

\section{Social networks in collaborations between academic research and firms ${ }^{1}$}

I worked with my co-author Marie-Pierre Bès on collaborations between firms and CNRS research laboratories within the "Engineering Sciences" department, where the public research has to prove also a mission in firms support (Grossetti and Bes, 2001). We analyzed more than a hundred collaborations, which at some time or the other were based on a contract. The method consists at first, in collecting information from a CNRS data base which lists all the contracts signed between the CNRS units and outside partner (about 14000 contracts signed with firms between 1987 and 1998). We selected some researchers who were scientifically responsible for some of these contracts and we asked them to describe several collaboration experiences in order to collect some data on the genesis and on the evolution of the collaboration. Each story collected from one researcher was completed by interviews made with industrial partners or other participants (other researcher, doctorate financed in the frame of this collaboration, help given by employees from external organizations, colleague, and so on). We realized 27 initial interviews with researchers, which generated 130 stories, which themselves were completed with 119 interviews (73 with industrial partners, 46 with other researchers or participants). The researchers initially questioned belong to teams located in Toulouse (11), Bordeaux (5), Montpellier (3), Clermont-Ferrand (2) and Grenoble (6); most

\footnotetext{
${ }^{1}$ This section and the next show in part a presentation given in a previous article (Grossetti, 2008).
} 
of the SPI (sciences for Engineering) are represented: electrical engineering (1) electronics (7), automatics and robotics (3), computing (5), chemical engineering (4), fluid mechanics (7). The 130 relationships involve 81 partners, in which 38 major companies ( 73 relationships), 35 small firms (38 relationships) and 8 are public organizations of technological research which we choose to include because they played the part of true industrial partners in the stories collected. $36 \%$ of these relationship are located in the same region (the research and the firm are located in the same region), 38\% associate a provincial laboratory and a firm located in the Paris region and $26 \%$ a research laboratory and a partner from another region or country.

We grouped the situations encountered into three categories, corresponding to the three figures displayed above. In the first category - network logic - the contact results from the existence of a pre-existing relation chain linking the people who made the decision to collaborate. This is the most frequent category ( $44 \%$ of cases). The decisive relation (the one that serves as bridge between the organizations) derive mainly - in four out of five cases from teaching (former students, professor/student) or from professional activity (colleagues). It is mobility within local job markets that explains most of the local relations that we observe (Grossetti, 2007). People maintain links in the organizations they have passed through (university, companies) and these links can be mobilized in their professional activity. In the second category - the intervention of intermediary organizations - contact is established under the aegis of an external player who, willingly or otherwise, causes interactions between members of the organizations, which will then be led to collaborate. For example, a ministerial agency appointed one of the laboratory researchers and a member of the company to a limited group of experts who then decided to engage their respective organizations in cooperation. Or, again, a local organization seeking to promote exchanges between labs and companies intervened to put the two organizations in contact. This category is less common than the previous one $(18 \%)$. Finally, in the third category - use of mediation resources contact results from the partners' initiative (based on public information, as for example scientific publications) or their meeting at a collective event (conference, trade show). Or the contact may be the result of the functioning of the student in-service training market: a student responds to a broadly distributed offer for in-service training, and the negotiations place the future partners in contact (the professor organizing the in-service training and the manufacturer taking in the trainee) who then decide to pursue their collaboration by other means. This third category accounts for $38 \%$ of cases. When we cross these meeting logics and the partners' location, we get results that clearly lobby for explaining proximity effects by the existence of local personal networks. Although the correlation is clear, we need to be careful not to confuse local relations with the logic of networks, since the latter applies broadly to cases in which the partners are distant. Furthermore, these other two contact logics may also be involved in the genesis of local relations. One way to explain the correlation is to say that these relations favor local relations more than the other modes of bringing entities together, because the intermediary organizations are for the most part at the national level (in France's case) and the mediation resources are not very local. Science-industry relations are therefore partly dependent - through personal relations - on other types of exchanges such as the teaching activities of researchers and the job market.

However, there is a limit to the embedding of relations between organizations in personal networks. In our data, the logics of contact between companies and laboratories do not appear to be correlated with the location of the laboratories studied, with the type of partners, with technological content, or with the duration of the collaboration. It is as if the partners' geographic location were the main consequence of the context of formation of the collaboration in its unfolding. Overlooking the conditions of construction of the relation 
involves processes that may produce "decoupling," i.e., a weakening of the dependence on relations between organizations in relation to personal relations or, in contrast, a strengthening of this embedding. These well-known processes range from the formal legal framework constituted by the contract to the technical systems that allow joint work (prototyping, modelling, specific software, instruments, data produced, hardware, intermediate documents) and include the internal rules of organizations. In our analysis, we have stressed another process, "personification," which is founded on the involvement of particular social actors who, for a time, embody the relation: trainees, co-funded doctoral candidates, researchers or on secondment. For a time, these actors belong to both groups. It might be said that they belong to the collaboration group and the project group associated with it. In more than nine out of ten cases, collaboration relies on the work of these intermediary actors. Like material intermediaries, human intermediaries contribute to making the relation partially independent of the groups involved. At the same time, to the extent that $\mathrm{PhD}$ students or trainees tend to get recruited by participating companies, and the engineers or researchers maintain relations with their old colleagues, this fourth process produces embedding in the social networks and may contribute to undoing the decoupling that resulted from the three preceding ones.

Studying the relations between academic laboratories and firms gave us arguments against explaining proximity effects by the constraints of exchange of tacit knowledge. Indeed, we have never encountered a case in which engineers or members of the companies went regularly to the partner laboratories outside of the three or four annual project coordinating meetings, a frequency that practically never changes and in no way differentiates local relations from others. When cooperation requires major exchanges, which happens frequently but not systematically, there is generally a doctoral candidate who stays for successive periods, more or less long, in the laboratory and in the company. The technical constraints that may be involved in working at two sites distant from one another are easily compensated by methods like double prototyping (in electrical engineering, for example), in which a prototype identical to the system to be designed is created simultaneously at the laboratory and in the company. The idea that members of the company seek to appropriate the researchers' knowledge, tacit or otherwise, no longer stands up to analysis. What interests the companies questioned is the result and not necessarily the methods or concepts, but if that is the case, recruiting a doctoral candidate resolves this issue. However, that does not mean that there is no tacit dimension in these exchanges, but they in no way explain spatial proximity effects. Long-distance collaborative work is not especially difficult so long as certain participants are able to travel without a problem, and the technical and organizational set-ups are adapted to this situation. It might therefore be thought that the constraints of exchange of tacit knowledge do not explain the choices of location of companies resulting from research.

\section{Social networks in startups creation}

In another study, with Jean-François Barthe and other collaborators, we studied the creation of innovative companies (Grossetti and Barthe, 2008). We decided to consider the creation of a company as a complex process that involves many actors, and especially different levels of action. In this process, the founder or founders, considered as individual actors, give rise to a collective actor, an organization, by mobilizing resources and relying both on individuals and on existing organizations, sometimes in a more global milieu or an established market. We were especially interested in situations of access to resources. Mobilization of a resource is a sequence of actions in which one of the creators mobilizes or receives a resource he does not have. For example, consultation with an attorney to draw up the articles of association is a 
sequence that involves one or more creators, the attorney, and the advice he dispenses. The attorney may be a relation of one of the creators, or a relation of a relation, in which case we consider that mobilization of the resource is achieved through social relations, or he may have been selected from a directory, in which case we consider that this is a mediating resource that allowed access to the resource. Hence, for example in case $n^{\circ} 107$, the sentence (made anonymous here) "The articles of association are drawn up voluntarily by an auditor whom [the creator] met while dancing" makes it possible to code that the resource is a counsel, that it was obtained through mobilization of a relation (by a relational chain of length 1), a relation established during leisure time. For the 53 companies we studied, the number of situations of resource mobilization averaged 16 per history (the minimum is 2 and the maximum 34), or 870 in all.

The first result is that social relations occupy a predominant place in the processes of company creation: $57 \%$ of the coded situations involve calling on relations. Relations are more present in the initial phase, before filing of the articles of association (64\% of situations of access to resources involve relations). The following phases leave greater space to mediation resources $(60 \%$ of access to resources through these mediations during the second year of existence), which illustrates the idea of a progressive decoupling of the new organization vis-à-vis the relations of its founders. It is as if the organization little by little succeeded in making itself independent of the founders' relations, as if the initial embedding, essential to its creation, gradually weakened to the benefit of non-relational logics. The relations mobilized are above all professional ones ( $80 \%$ of cases), but quite often connoted affectively ( $36 \%$ of these relations are "friendly-professional"). The other modes of access to resources can be divided into two categories. The first consists of professional or public bodies, which are the equivalent of the intermediary organizations seen in the study on relations between laboratories and companies. This mode of access to resources is present in $27 \%$ of cases. The second category includes mediating systems, which may be media, various human mediators, seminars, trade shows or fairs. They represent $16 \%$ of cases. Social relations tend to favor access to local resources, just as intermediary organizations do, whereas mediation resources are slightly less oriented towards local resources. The result is close to the preceding study, but the intermediary bodies here are more local. The resources mobilized are overwhelmingly local. Customers are the only type of resource not primarily local in origin.

Of the companies studied, some came out of academic research labs or used research results. The tacit-knowledge constraint does not appear here more than in the preceding study. In general, companies recruit young doctors coming out of laboratories in order to apply and develop technology, which resolves the problem of knowledge transfer. Location choices are therefore not closely linked to this constraint. Rather, they are explained by the initial location of the founders (whether the researcher or a collaborator): in general, people create companies where they live (and where their families live).

Social networks that underpin industrial clusters are largely made up of people who have studied in local universities and schools. They have little to do with arrival in the city of creative professionals attracted by the quality of the urban environment.

\section{The mobility of creative workers}


I was recently involved in a European study of the creative class (Martin-Brelot, Grossetti et alii, 2010). This research project entitled 'Accommodating Creative Knowledge Competitiveness of European Metropolitan Regions within the Enlarged Union' (ACRE) was carried out within the Sixth Framework Program. The ACRE project includes several research steps, some of them based on quantitative data, others more on qualitative methods. This article is based on quantitative data deriving from a questionnaire survey that was carried out in 11 participating cities 2 in 2007, and resulting in more than 2,300 questionnaires filled out by professionals considered to be 'creative'. These empirical data provide a solid basis to test hypotheses on mobility of the creative class and the supposed role of 'soft' factors in attracting creative people (Florida, 2002).

The majority of respondents in our survey were born or studied in the region where they currently live, which suggests that not only international but also long-distance national migration plays a subordinate role in their life. This can be explained by the strong embeddedness of European talent workers in the local labor markets through personal networks, or the particular functioning of the housing market in European countries, which may impede mobility. So, Florida's theory doesn't apply to the European context. The fact that Europeans are less mobile than North Americans is only the first possible answer. In addition, our results, combined with American criticism of Florida's theory, also suggest another explanation: the theory has serious defects, at least regarding its geographical aspect. The theory relies heavily on a model of mobility where workers are not only liable to change location, but also make location choices in the same way that they choose a trip for a vacation week, comparing cities and their quality. This model does not take into account that workers are linked to particular people or to particular places where they have lived before. It also overestimates the importance of choosing a city when workers move to another job, and it underestimates the importance of choosing the neighborhood within an urban area. It may be less important to choose between Milan and Munich than between one district and another in Milan or in Munich. For creative people searching for a location, hard factors (mainly quality of jobs) are the reasons why they choose a particular city and soft factors determine why they choose a particular district. Florida's model may work for single young professionals or bohemians looking for inspiration or a quick career move and ready to take off at any moment if they see a better chance. But it does not seem to apply to families with children of school age, for whom the prospect of living with another language and a novel cultural environment may be a serious obstacle. It may also not work for middle-aged couples, where one of the partners is professionally connected with a particular European area or where adjusting to other pension regulations would have to be seriously considered.

I now use these studies, and some others, to propose a reflection on policies meant to facilitate local economic development based on innovation activities.

\section{What are the conditions necessary to develop and innovate using local scientific - industrial relationships?}

Of course, innovations are not necessarily based on relationships between science-industry and when this is the case, these relationships are not necessarily local. Numerous technical innovations have emerged without links to scientific research or even to higher education, from weaving looms of the first industrial revolution to the recent microchips. When innovations take place at the interface of two worlds, they can be done by remote 
collaborations, neither do they imply the existence of local "clusters"2. If I am interested in innovation activities based on local relationships between companies and academic organizations, it is because they are subject to numerous policies - those that I listed in the introduction - and in this paper I 'm interested on the effects of these policies. I use the term "innovation activities" to sidestep the difficulty involved in assessing the level of innovation in a recently developed product or service, when lacking the necessary historical perspective. If we consider that innovation is a product or service that has found a new market, it may take time and it is impossible for an analyst to comment on the short term. In contrast, we can easily identify "industrial worlds" that are organized around the production of technical innovations, for example in the field of digital technologies or that of biotechnologies. This means that companies rely on technological innovation to make a profit and that significant activity is oriented towards the production of such innovations. If "innovation activities" as defined here do not produce real innovations, we can assume that they could not continue in the long term, even if the government support or investment from large industrial groups can maintain them for some time.

What are the necessary conditions that make an innovative industrial cluster involving local scientific and industrial relationships possible?

The first is local industry, whether coming from institutions created by outside companies or from the creation of new local companies. Therefore the first ingredient is an analytical process stemming from their industrial history. In most industrial clusters, it is rare to have settlements of outside companies. Moreover, moving sales offices or facilities of service companies headquartered elsewhere to seek benefit from the market created by the economic dynamism of the cluster can be detected. The basis of the cluster generally consists of firms created locally, whether they be old and or have experienced changes in their business and the technology they use. When this is not the case, there is a strong political incentive, as was the case in France for the business park of Sophia-Antipolis, which benefited from national policies that encouraged some public research organizations and firms to settle there. Of course, there are firms, or industrial groups, which are likely to settle in cities that compete to attract them, but it is relatively rare compared to the movement for the creation of local firms.

The second necessary condition is the presence of institutions of higher education and research. While in some countries like the United States or Germany, there has always been a decentralized network of universities, many other countries have a much more hierarchical network whose density increased over time. In this context, obtaining the creation of a university, an institution of higher education or a research organization, is naturally an important issue. Analyzing such settlements and developments is the realm of scientific, institutional historians. If a city has both enterprises and institutions of higher education, local research initiatives must still be compatible. Industrial sectors and scientific specialties may not always be so, creating additional problems. An obvious, but relevant reminder is that connections are more easily established between a department of electronic engineering and the same industrial sector than that between a department of mathematics and basic manufacturing companies in paper pulp.

Therefore two historical processes converge at once. I want to make two statements on these processes: 1) in some cases, industrial history and the history of scientific institutions can

\footnotetext{
${ }^{2}$ I use here for convenience the term "cluster" proposed by Michael Porter (1990) to describe spatial concentrations of firms and other organizations in interaction that were called before "districts", "local industrial systems", or sometimes "technopoles".
} 
be totally separate; 2 ) various industrial or scientific processes can lead to similar results. The first assertion can be supported by examples in which a scientific institution has grown into a town in the total absence of stimuli coming from the local industry, for example as a result of a policy, like in the case of engineering in Toulouse between 1900 and 1980 (Peyroux et al, 2010). And we could present similar examples of industrial processes. The second assertion is based on the observation that the similarity of current industrial systems may still have very different histories. I had the opportunity to compare the industrial history of Toulouse and Grenoble and I found that while the former city has benefited from significant national and local policies to create separate industrial and scientific basis, that have later established collaborations, the latter saw these collaborations develop very quickly, and its industrial and scientific system developed interactively. There is no single historical path towards the formation of innovation clusters. They are the result of a history of structural logic, policies, industrial strategies and contingencies.

Let's suppose that a city is equipped with an industry and a scientific system which is compatible, it is still necessary to establish mutual exchange. So called "proximity effects", are involved here, that is to say that when "all non geographical things that we have designed to measure are made equal", there are more local relationships (on the scale of urban areas) than should be. I would like to add three assertions about the effects of proximity. The third assertion is that proximity effects are independent of the historical processes of constitution of the concentration of companies and scientific institutions. Of course, they can reinforce them, interact with them, but it is by no means a necessity. They must be studied separately from these historical processes. The fourth assertion is that these effects are due mainly to the embedding of exchanges between organizations in networks of interpersonal relationships. This is a classical theory since the work of Granovetter (1985) and, in the case of clusters of innovation, the study of AnnaLee Saxenian on Silicon Valley and Route 128 (1994). It is also true in France (Grossetti, 2008) and in most contexts where these effects have been investigated through field work. The embedding logic explains the main part of the effects of proximity, but they can also have other causes, such as public facilities. Simply put, in all cases studied, the embedding logic prevails, whether combined or not with other factors. Constraints on the exchange of tacit knowledge, which were sometimes referred to by scholars to explain the effects of proximity in science-industry relationships (Zucker et al, 2002) do not seem so important: most often industry does not seek to appropriate knowledge to researchers, but rather their results. In the rare cases where they need to acquire this knowledge, firms can recruit researchers, possibly temporarily, or send their own researchers to collaborating university laboratories, without locating the company near the laboratory.

Finally, the fifth assertion is that proximity effects are spread mainly across the urban area and not on the scale of technological parks and smaller spaces. This assertion is consistent with what is known about the geography of personal networks, most of which tend to concentrate in urban areas, although some may continue strong ties despite the distance. And from the links listed in the town inhabited by respondents, relations from the same neighborhood are the minority. This does not mean that there is no specific effect related to proximity at the level of the neighborhood, the block or the building. But these effects are much lower than those in the same city; that is broadly speaking, at less than an hour of low cost transport. In the case where parks are inserted into an urban area, in general, a particular densification of network collaborations across parks is not observed, once the effects of industrial or scientific specialization are neutralized. When we empirically study the genesis of collaborations between companies or between companies and laboratories, there is no 
empirical case where collaboration is born from a meeting in a cafeteria or in front of a coffee machine between people who not previously know each other. In our study of scientificindustrial collaborations conducted in France in 2000 (see above), Marie-Pierre Bes and I did not observe random meetings in a public place. This result is consistent with the studies on social interaction (Goffman, 1967) which show that being in the same public space does not necessarily produce interaction: in general, taking the subway with other people will not generate interaction with these people, except at the subway's failure or other rare occurrences.

This summary outlines what is to me a set of results obtained on specialized innovative clusters, even if not all of them are unanimously cited by researchers working in this area, particularly regarding the explanation of proximity effects. Stating these results outlines elements for policy evaluation in the future creation or development of these clusters, but I will look more systematically at the policies.

\section{Assessing the effectiveness of local policies to promote innovation}

I introduced above a kind of typology of these policies, some of which are very old (although still in circulation) while others are much more recent. I'll start with the oldest, those on higher education and research.

\subsection{Policies on higher education and research}

The history of recruiting Chaptal by the states of Languedoc in 1781, which I mentioned in the introduction, can be interpreted as an effort by local authorities to guide an existing university to its' industrial applications. It may seem that this type of policy has been quite common in history, but by looking more closely at these cases, we realize that this is rarely an initiated by local authorities, rather it is the outcome of lobbying by some application-oriented scientists who are seeking resources for their research. For example, when considering the establishment science departments in technical institutes in France between 1880 and 1914, we realize that, even when these institutes have industrial or public funding, it is always the teachers who instigate their creation (Paul, 1980). These policies can have significant effects even when developed by those who are the direct beneficiaries. It can be argued that Grenoble, Nancy and Toulouse's sustainable orientation of their respective science departments towards engineering originated with the creation of electrical institutes, which then resulted in a significant over-representation of this type of higher education institution and laboratory in the current scientific make up of these cities (Grossetti, 1995). In some cases the orientation has been accompanied by industrial development based on the same types of skills (Grenoble), while in other cases, the enlarged engineering degree programs and research found no echo in the local industry over many decades (Toulouse).

For this type of policy to be established, it is necessary that cities have universities and this is not always the case. Another policy is therefore simply to obtain the creation of a university. In some of the historical and national contexts, such as France, the cities do not have the right to establish universities. Their representatives therefore rely on lobbying for favorable government decisions. Thus, in the French system for the period 1808-1870, academic departments, faculties were created by government decision. The faculty of science were rare at the beginning of that period, and have seen their numbers increase over the different waves 
of creation. Each time, fierce competition has pitted cities that are geographically close (Rennes and Nantes, Nancy and Metz, etc.) against each other to obtain new schools. More recently, in the 1960s and 1990s, during two periods of French higher education expansion, cities with no university have influenced the "scientific map" by funding "antennas" of universities based nearby, with the long term objective to obtain the government funding for these antennas to becoming comprehensive universities In other national contexts (Portugal, 1990-2010), it is possible to establish private universities without having to obtain the consent of the government. Cities can then intervene more directly, by stimulating and supporting private initiatives. Having a university is always an advantage for a city because it secures a younger population pursuing university studies and maintains or increases a mass of local consumers. It also allows local businesses to have a skilled workforce and exchanges with scientists. But not all universities are in a position to contribute to the emergence of specialized, innovative clusters, rare is the case, as it requires the presence of companies likely to connect with high level university research.

A variant of this kind of policy is the one that aims to establish a government research center. In the French case, the choice of location outside Paris, such institutions (nuclear research center in Grenoble, space agency in Toulouse, telecommunications development center in Lannion in Brittany) were the result of lobbying by representatives of the cities, enabling their networks in government. The effects of these institutional creations were varied. In the case of Lannion and Toulouse, these effects are important because the establishments were both industrial operators as well as technical development centers. In Lannion, this implementation has generated an entire industry of telecommunications. In Toulouse, the space center has become the basis of a cluster of industrial space activities, including a research laboratories and training in electronic engineering and computer science that were already in place, thus initiating economic development based on engineering activities.

\subsection{Policies on industrial development}

To strengthen local industry, one can try to encourage the installation of outside companies or to create institutions supporting the creation of local businesses. In general, local governments are trying to combine the two aspects.

To attract outside companies, cities often rely on the creation of amenities such as business parks and technology infrastructure, thought to be sought out by companies. The idea is to attract companies looking for a place to set up by arranging the space for it. This is somewhat reminiscent of the famous cargo cult that the Melanesians developed. In this myth, which includes many variants, cargo is wealth that came by means of ships or planes. For Melanesians, whites did not work, they could only get these riches sent by their ancestors through magic. Thus, the Melanesian began to build mock docks, radios and runways, to attract Cargo (Worsley, 1957). Somewhat the same way, the myth of the attraction of companies assume that simply putting in place the necessary conditions (business services, industrial areas, local roads and communication) is sufficient for making companies settle there. Certainly, it is necessary to accommodate businesses and provide them with the resources they need to operate, but this approach often forgets the real logic of setting up a business location. First, new locations involve few companies and virtually all cities are in competition with each other, further, most of them (in the same country) have comparable assets. Then, in general, a company does not choose its location because local amenities or because tax exemptions (except in the case of very large groups of institutions searching for a 
location across the country or continent). The choice of location comes from more traditional economic factors (proximity to markets or resources), and in some cases from subjective factors, more complex than just tax benefits and existing infrastructure (e.g. geographical origin and social networks of leaders, especially for small and medium enterprises). In France, some implementations of large companies (in Sophia Antipolis or Toulouse for some companies) are the result of political lobbying and the activation of social networks much more than an examination of the costs and benefits. When a technological park fills up (this is the case in France for Grenoble or Toulouse parks for example), it is mainly by companies already established in the same city.

To promote the creation of local businesses, local governments generally create support services, business incubators, and sometimes venture capital organizations. In a study on the creation of innovative companies in various French cities, we could verify that these structures are actually used by local entrepreneurs (Grossetti and Barthe, 2008). Two thirds of entrepreneurs used the support services for start-ups at least once, for legal and business advice. Many are welcomed in a nursery or in an incubator, but it is mainly to have inexpensive accommodation. Finally, the local venture capital organizations are often involved, but they only support a limited number of projects, which explains why entrepreneurs are often critical of them. It seems that this type of policy is a little less random than looking for outside locations by the development of technology parks.

\subsection{Policies to foster relationships between firms or companies and laboratories}

Technology parks are also expected to promote local exchanges, providing meeting opportunities to companies or laboratories. They are often accompanied by mediation activities organized by people who are specialized in these areas and who are paid by local authorities.

If we summarize the achievements of the empirical studies mentioned in the first part, we can emphasize two points. 1) The business parks do not produce "synergies" ... Regarding parks located in large cities, the results contradict the idea that they are sources of synergies: local social networks are not built on the basis of this closeness, but mainly through the participation of members of companies or laboratories for routine activities (studies, work, etc..) that are spread over a wider area. In large cities with high rates of technological activities, parks are filled because they meet certain business needs (accessibility, working comfort, image, etc.) but are not the source of local exchanges between productive organizations or scientists. We did not observe either a "cafeteria effect" or any "coffee machine effect" in connecting people who are not already connected. In a sense, the city itself is enough a "park" to cause proximity effects. Moreover, by encouraging employees to reside in the periphery, technology parks contribute to urban sprawl and social segregation (some nearby municipalities become "white collars ghettos"). 2) ... but human mediators do produce some. In the study of collaborations between laboratories and companies mentioned above, we found several cases in which contact was initiated by a person whose function it was to facilitate these exchanges, (a local representative of the national agency for innovation, a university administrator that specializes in personal links with business, a local government service person responsible for communication with companies etc.). Some activities (working groups on technical standards, for example) have also led to collaborations. These actions can be effective across a metropolitan area and are in no way dependent (if not a political choice 
for local authorities) of the concentration of scientific and industrial establishments in a technology park.

\subsection{Policies oriented towards attraction of "creative" workers}

For regional economist Richard Florida, a "creative class" exists in our societies: it groups together those who, in today's economy, develop new ideas, technologies and creative content (Florida 2002). This class covers a wide variety of occupations, he cites among others, hightech business, entertainment, journalism, finance, or crafts. Florida also adds a theory of economic development of cities by attracting creative class members to the concept of the creative class. According to this author, the members of the creative class choose the cities in which they will settle on the basis of qualities such as urban environment, openness to minorities or the vitality of cultural activities, thus "soft" urban factors, rather than traditional "hard" factors such as employment, wages, or infrastructure.

In the world of urban policies technicians and local elected officials, the attraction of these "creative" professionals has emerged as the solution for urban development policies as it is inexpensive and successful in the short term: it may seem easier to attract persons than whole companies, or, more costly, to foster endogenous development by financially supporting education and research. This thesis has prompted policies to attract a small elite scientific, cultural or business, through direct incentives, or facilities expected to match the tastes of this social stratum. In a study of the "creative" professionals in 12 European countries (MartinBrelot et al., 2010), we showed that these professionals are relatively non-mobile, a majority of them were born or have studied in the town concerned. Those who settle in a city they have not previously lived in come most often employment and salary concerns. Cases that correspond to the theory of attracting creative by "soft factors" represent less than $1 \%$ of interviewees. Similar results were obtained in surveys in the United States (Scott, 2006). In fact, the problem is somewhat similar to the attraction of business: geographic mobility is too low for allowing this type of policy being effective. However, it seems that what we can keep from the creative class thesis is the idea that urban environmental factors are important, in attracting students for temporary stays, and also in retaining "creative" professionals that might seek to escape an unfavorable environment.

\section{Conclusion}

Policies fostering innovation may be on quite varied scales of time and space. Some focus on very limited areas (technology parks) supposed to promote innovation through concentration, others focus on the urban level, others go beyond (county, region). Some policies are shortterm (developing an activity area, advertising for the site), others medium term (implementing operations, creating structures of venture capital), others in the long term (development of teaching and research institutions).

The examples that I have shown suggest that urban areas are the most relevant geographical scope. This is the scope of deployment of "spontaneous" cooperation, networks, and labor market. Further, this is the level at which most proximity effects occur as they are lower either below or above (excepting the nationwide level). In terms of time frame, the results are more complex. The longer-term policies, including those relating to education and research, are often the most effective, although some shorter-term policies may be useful in a more 
restricted way. In particular, such is the case with human mediators or coordinators whose actions are well integrated in the local networks of research and industry. Infrastructure such as technology parks may not be very useful, overall it seems humans are more effective than concrete......

\section{References}

DiMaggio Paul and Zukin Sharon (eds) (1990), «introduction», in Structures of Capital. The social organization of economy, Cambridge University Press, 1-36

Etzkowitz Henry (2002), MIT and the rise of entrepreneurial science, London and New-York: Routledge.

Florida, Richard (2002), The Rise of the Creative Class and How It's Transforming Work, Leisure, Community and Everyday Life, New York: Basic Books.

Goffman Erwin (1967), Interaction Ritual: Essays on Face-to-Face Behaviour, New-York: Doubleday, Anchor Books.

Granovetter Mark, S. (1985), "Economic action and social structure: the problem of embeddedness", American Journal of Sociology, 91 (3), 481-510.

Grossetti Michel and Jean-Marc Zuliani (2011), "Toulouse and the On-board Systems Cluster: a Late Result from One Century of Local and National Policies", Brazilian Geographical Journal: Geosciences and Humanities research medium, Uberlândia, 2 (2), 323-336.

Grossetti Michel and Jean-François Barthe (2008), « Dynamiques des réseaux interpersonnels et des organisations dans les créations d'entreprises », Revue Française de Sociologie, 49 (3), 585-612.

Grossetti Michel (2007), «Are French networks different? », Social Networks, 29, (3), 391404.

Grossetti Michel (2008), « Proximities and embeddings effects », European planning studies, 16, (5), 613-616.

Grossetti Michel and Marie-Pierre Bès (2001), «Interacting individuals and organizations: a case study on cooperation between firms and research laboratories », in Alan Kirman and Jean-Benoît Zimmerman, Economics with heterogeneous interacting agents, New-York, Berlin, Heidelberg: Springer, 287-302

Grossetti Michel (1995), Science, industrie et territoire, Toulouse : Presses Universitaires du Mirail. 
Martin-Brelot, Hélène, Grossetti, Michel, Eckert, Denis, Gritsai, Olga and Kovács Zoltan (2010), "The spatial mobility of the 'creative class': a European Perspective, International Journal of Urban and Regional Research, 34 (4), 854-870.

Paul Harry W. (1980), "Apollo courts the Vulcains. The applied science institutes in nineteenth century French science faculties" in Robert Fox and Georges Weisz, The organization of Science and technology in France, 1808-1914, Paris: MSH, 155-182.

Peyroux Elisabeth, Grossetti Michel, Eckert Denis 2009, «Becoming a knowledge city »: the example of Toulouse », Built Environement, 35 (2), 196-203.

Saxenian AnnaLee (1994), Regional advantage, Cambridge (Mass.): Harvard University Press.

Scott Allen J. (2006), "Mainsprings of the Creative City: Lessons for Policy-makers”, OECD Territorial Reviews: Competitive Cities in the Global Economy

Zucker Lynne G., Darby Michael R. and Jeff S. Armstrong (2002), "Commercializing knowledge: University Science, Knowledge Capture, and Firm Performance in Biotechnology”, Management Science, 48 (1), 138-153 